\title{
DEMOCRACIA REPRESENTATIVA, DEMOCRACIA PARTICIPATIVA E QUESTÓES IDENTITÁRIAS: OS EVANGÉLICOS COMO UM CASO BOM PARA PENSAR ${ }^{1}$
}

\section{Alexandre Brasil Fonseca ${ }^{2}$}

\begin{abstract}
Resumo: Neste artigo - em diálogo com o texto de Christina Vital da Cunha reflito sobre a relação entre democracia participativa e representativa e como a inserção em partidos políticos envolve elementos importantes que contribuem para a discussão sobre as questóes identitárias e suas contribuiçóes para se pensar a política formal. Saliento que considerar a presença de evangélicos na vida partidária, junto às estratégias e diretrizes político-partidárias existentes, como também nos processos de financiamento eleitoral e na estruturação das campanhas são aspectos importantes para a análise proposta. Como conclusão indico que me parece que as diferenças identificadas não são só geracionais, há componentes de classe e questôes relacionadas à inserção no território, envolvimentos com diversos movimentos, militância e os diferentes tipos de inserção nas estruturas partidárias.
\end{abstract}

Palavras-chave: IURD; Evangélicos e Política; Eleições; Partidos Políticos.

\section{REPRESENTATIVE DEMOCRACY, PARTICIPATORY DEMOCRACY AND} IDENTITY: EVANGELICAL CHRISTIANITY AS A GOOD CASE TO THINK

\begin{abstract}
In this article - in dialogue with the text by Christina Vital da Cunha - I reflect upon the relationship between participatory and representative democracy and how the insertion in political parties involves important elements that contribute to the discussion on identity and their contributions to think about formal politics. I emphasize that considering the presence of evangelicals in party

\footnotetext{
${ }^{1}$ Como citar: FONSECA, Alexandre Brasil. Democracia representativa, democracia participativa e questóes identitárias: os evangélicos como um caso bom para pensar. Debates do NER, Porto Alegre, ano 21, n. 39, p. 137-153, 2021.

${ }^{2}$ Professor e diretor do Instituto Nutes de Educação em Ciências e Saúde da Universidade Federal do Rio de Janeiro, Brasil. E-mail: alexandre.fonseca@nutes.ufrj.br. ORCID: https://orcid.org/0000-0002-7495-4902.
} 
life, together with the existing party-political strategies and guidelines, as well as the electoral funding processes and the structuring of campaigns are important aspects for the proposed analysis. As a conclusion I indicate that it seems to me that the differences identified are not only generational, but there are also class components and issues related to insertion in the territory, involvements with various movements, militancy, and the different types of insertion in party structures.

Keywords: Universal Church of the Kingdom of God; Evangelicals and Politics; Elections; Political Parties.

Ao ler o artigo de Christina Vital da Cunha sobre evangélicos de esquerda nas eleições municipais de 2020, uma questão que me pareceu central está relacionada à discussão sobre democracia representativa e democracia participativa. Como assinala Avelar (2007), ao discutir a participação de mulheres na política partidária, há um nó górdio que precisa ser desatado e que envolve a ligação entre as políticas identitárias e a política representativa.

$\mathrm{Na}$ reflexão apresentada, a questão das "performances e articulações identitárias" são demarcadas por realidades que perpassam candidatos nas eleiçôes municipais de 2020, acompanhados pela pesquisa, que associam questóes de gênero e de raça à filiação religiosa. Esse aspecto, de fato, como a autora salienta ao final, é um "caso bom para pensar" a política na atualidade, considerando, particularmente, que cada vez mais é possível identificar tanto a centralidade da religião na política, como também o aumento de processos de "religiogização da política" (Novaes, 2001).

Pensar sobre aspectos que considerem esse outro patamar na discussáo proposta por Vital da Cunha é útil para se ter uma melhor percepção do momento e das disputas que envolvem a participaçáo dos evangélicos na política nacional. No texto é feito um importante resgate buscando dialogar com realidades anteriores, como no caso de formação do Movimento Evangélico Progressista (MEP), considerando proximidades e diferenças com experiências como a da Frente de Evangélicos pelo Estado de Direito (FEED). Em relação ao movimento negro, uma interessante discussão é feita ao revisitar o importante material publicado na década de 1980 pelo 
ISER em projeto coordenado por Regina Novaes e Maria da Graça Floriano. Sobre a questão de gênero, também retorna ao passado, em trabalhos da década de 1990, para situar em perspectiva mais ampla essas discussóes.

Esse é um aspecto importante a salientar da discussão apresentada pela autora e que parece estar ausente em relação a alguns dos depoimentos citados, como no caso de Jackson Augusto, importante liderança do movimento negro evangélico, que em sua fala sublinha os acontecimentos entre 2013 e 2020 para apresentar a base de sua compreensão do momento político atual. Essa compreensão se dá, conforme o texto aborda, em considerar a inserção de segmentos evangélicos jovens na disputa eleitoral tendo como importante motivador a atuação em questóes identitárias que envolvem diferentes movimentos e organizaçóes na recente história brasileira. A presença midiática de algumas das personagens mencionadas no texto é significativa, seja por sua atuação nas redes sociais, seja pela projeção que receberam a partir da veiculação de reportagens na grande imprensa. Vale sublinhar que os dois artigos mencionados, que foram veiculados pela Folha Universal, se deram exatamente como uma reação a matérias que tiveram grande repercussão nas redes sociais com grande alcance de público.

Em 5 de julho de 2020, na coluna de Mônico Bergamo da Folha de S. Paulo (FSP), foi publicada uma matéria com o título "Lideranças religiosas criam Bancada Evangélica Popular para lançar candidaturas”3. E, não por acaso, no dia 31 de julho de 2020 foi publicada a matéria comentada por Vital da Cunha na Folha Universal (FU) com o título "O que está por trás da Bancada Evangélica Popular: Grupo de esquerda deseja criar uma bancada socialista voltada para cristãos" ${ }^{3}$. O mesmo acontece no mês de

${ }^{3}$ BERGAMO, Mônica. Lideranças religiosas criam Bancada Evangélica Popular para lançar candidaturas. São Paulo, Folha de São Paulo, 2020. Disponível em: https://www1.folha. uol.com.br/colunas/monicabergamo/2020/07/liderancas-religiosas-lancam-bancada-evangelica-popular-para-lancar-candidaturas.shtml. Acesso em: 24 jun. 2021.

${ }^{4}$ FOLHA UNIVERSAL. O que está por trás da Bancada Evangélica Popular. 2020. Disponível em: https://www.universal.org/noticias/post/bancada-evangelica-popular/. Acesso em: 24 jun. 2021. 
setembro. Dessa vez foi a publicação de uma matéria no Portal do UOL que obteve grande alcance na Internet no dia 9 de setembro de $2020 \mathrm{com}$ o título "Bancada evangélica de esquerda surge contra neopentecostais e conservadores". Também a FU publicou uma "resposta" no dia 27 de setembro em uma matéria com o título "Bancada evangélica de esquerda? Trata-se de um grupo de pré-candidatos a vereador. Entenda por que esta onda não se sustenta"'.

Sobre essas "respostas", um ponto interessante é a repetição das mesmas expressōes nos títulos da FU daqueles publicados nas matérias originais e que foram veiculados pelo grupo Folha. Obviamente, isso não é algo do acaso, mas sim uma concreta demonstração da preocupação e cuidado em relação a um melhor alcance na utilização dos mecanismos de busca da Internet. Ao procurar esses assuntos, ou mesmo as matérias originais, o leitor verá em seus resultados, em posiçôes próximas, os materiais veiculados pela FU. Mais uma vez, a IURD demonstra continuar atenta ao tempo presente considerando seriamente o papel dos big data em suas açóes desenvolvidas em meio à nossa sociedade imersa no capitalismo de vigilância (Zuboff, 2018). Essa segunda resposta não se deu apenas nas páginas dos jornais, na época também foi possível perceber a circulação via WhatsApp, e outras redes sociais, de vídeos com conteúdo desinformativo identificando como uma impossibilidade qualquer relação entre evangélicos e partidos de esquerda, numa citação direta a alguns partidos? ${ }^{7}$ Um vídeo ou similar também é citado por Vital da Cunha. Um ponto importante é que esse vídeo não está desassociado das matérias como uma "outra resposta", mas fazem parte de

${ }^{5}$ UOL. Bancada evangélica de esquerda surge contra neopentecostais e conservadores. Disponível em: https://noticias.uol.com.br/eleicoes/2020/09/09/contra-neopentecostais-1-bancada-evangelica-de-esquerda-se-lanca-em-2020.htm. Acesso em: 24 jun. 2021.

6 FOLHA UNIVERSAL. Bancada evangélica de esquerda? Disponível em: https://www. universal.org/noticias/post/bancada-evangelica-de-esquerda/. Acesso em: 24 jun. 2021.

${ }^{7}$ COLETIVO BEREIA. Mensagem anônima que circula em mídias sociais usa pânico moral contra partidos de esquerda. 2020. Disponível em: https://coletivobereia.com.br/mensagem-anonima-panicomoral/. Acesso em: 25 jun. 2021.

Debates do NER, Porto Alegre, ano 2I, N. 39, P. I37-I 53, JAN./Jul. 202 I 
um mesmo ecossistema de informaçôes articulado e que tem como objetivo promover a desinformação, assumindo conscientemente a disseminação da mentira como uma estratégia discursiva que visa favorecer determinado grupo em detrimento de outros (Fonseca, 2020).

Neste diálogo com o texto de Christina Vital da Cunha interessa-me, particularmente, refletir sobre a relaçáo entre democracia participativa e representativa e como a inserção em partidos políticos envolve elementos importantes que podem contribuir para o nosso olhar sobre as questóes identitárias e suas contribuiçốes para se pensar a política formal. Inicialmente é abordado um aspecto em que há uma rápida menção ao texto em debate em que cabe destacar alguns tópicos. Posteriormente comento a questão da atuação partidária, a qual me parece bem importante para o atual debate.

\section{OLHAR PARA O NORTE E PARA A ECONOMIA: UMA NECESSIDADE}

Provavelmente o livro de Delcio Monteiro de Lima, publicado em 1987, ficou mais famoso por seu título do que exatamente por seu conteúdo. "Os demônios descem do Norte" foi escrito em meio à uma época em que a presença norte-americana na política nacional de países da América Latina era bem intensa, numa política externa que dava suporte e promovia vários governos não democráticos. Os aspectos que associaram a atuação religiosa e as figuras dos televangelistas eram uma parte importante dessa história e foram explorados em vários trabalhos que associaram o período pós-guerra com o surgimento da Maioria Moral, da Nova Direita Cristã e com a ascensão do governo Reagan como elementos que demarcavam essa intervenção e auxiliavam a compreender a presença evangélica na política brasileira, particularmente a partir do final da década de 1980.

Ao se propor a discutir o neoconservadorismo, Lacerda (2018) aborda de forma interessante parte dessa literatura, desenvolvendo argumentos que ajudam a pensar a recente presença de políticos evangélicos no parlamento 
brasileiro, caminho com o qual Vital da Cunha dialoga, e que surge de forma pontual em seu texto ao mencionar a questáo dos EUA e do sistema econômico. Entendo que isso é parte importante dessa história, mas merece ser ampliada. Olhar a recente historiografia da religião norte-americana pode ser bastante útil para matizar as reflexôes produzidas no campo das ciências sociais sobre essa discussão, nos auxiliando a ter uma melhor localização das origens desses discursos e práticas nos EUA. São vários os trabalhos que trazem novas luzes e recolocam no início do século 20 a gênese de toda uma concepçáo que parece ter se extrapolado de forma mais significativa em meio à ascensão e queda do governo de Donald Trump (Fonseca, 2021). Essas questốes são particularmente importantes pela proximidade assumida $\mathrm{e}$ proclamada por Jair Bolsonaro em relaçáo ao ex-presidente norte-americano.

Ambos os políticos podem ser entendidos como representantes de um populismo autoritário, como explorado por Demirovic (2019). É nesse contexto que devemos pensar o governo Bolsonaro em sua relação próxima com lideranças do segmento evangélico. Essas lideranças se erigem na polarizaçăo, numa transformação reacionária da democracia que é alimentada por uma lógica de confrontação. Distorcem valores de solidariedade e de sentido comum, contribuindo para uma neurotização das pessoas. Menosprezam opinióes divergentes, se negam ao diálogo e assumem postura anti-pluralista. Demirovic, nesse texto, escrito em 2018, aponta que em momentos de crise a opção de líderes populistas autoritários não se pautaria pela solução dos problemas, mas sim em alimentar ainda mais as polarizaçôes e a buscar apoios em grupos abertamente criminosos e fascistas. O que ficou tristemente evidente no caso da Pandemia de Covid-19 com os dois países liderando os números mundiais de casos e mortes. Não fazer concessões é uma marca e a menção constante a "pânicos morais" movimenta seus discursos e de seus apoiadores. Daí em suas falas serem recorrentes a menção a assuntos relacionados à imigração, sexualidade, segurança pública, defesa da ordem, da família e dos valores tradicionais.

A associação dessas lideranças populistas autoritárias com evangélicos foi algo emblemático tanto no caso brasileiro como norte-americano. Aqui, um 
ponto importante a ponderar em relação ao texto é a presença de elementos entre evangélicos tradicionais conservadores nos EUA anteriores ao período da guerra fria e que estiveram, tanto lá como aqui, presentes entre evangélicos tradicionais desde o início do século 20. Uma origem importante desses discursos não é encontrada entre os pentecostais, mas sim entre os segmentos tradicionais. Grupos estes que estão tão presentes no governo Bolsonaro e que, atualmente, têm quatro Ministros em posição de destaque, filiados exatamente a essas denominaçóes ${ }^{8}$.

Questóes relacionadas ao que se convencionou denominar de anticomunismo e a existência de uma associação direta do cristianismo com o capitalismo parecem ter sido parte constituinte de todo o movimento originário dos grupos fundamentalistas no sul dos EUA, sendo algo de sua identidade que pode ser localizada no período entre guerras no início do século 20 (Carpenter, 1997; Kirby, 2018). Essa associação está muito presente e se avoluma, no caso norte-americano, a partir da promoção de uma forte postura anti-New Deal que envolveu lideranças evangélicas (Kruse, 2015; Philips-Fein, 2009, entre outros).

Por conta do escopo desse artigo-diálogo, não cabe o aprofundamento dessa questão, porém gostaria de salientar a importância que possui esse tópico que foi abordado pontualmente por Vital da Cunha, sendo que há uma enorme afinidade entre as práticas e os discursos que foram alimentados no berço fundamentalista norte-americano a partir da década de 1920 e que se encontram bem presentes nas acusações de evangélicos à esquerda vistas atualmente, as quais sustentam as lógicas e as práticas de grupos que dão forte sustentação ao governo de Jair Bolsonaro. Essas devem ser localizadas a partir da associação com o fundamentalismo norte-americano em suas

${ }^{8} \mathrm{Na}$ Casa Civil, o batista e General Luiz Eduardo Ramos, na Secretaria Geral o luterano Onyx Lorenzoni, na Educação o pastor presbiteriano Milton Ribeiro e na Advocacia Geral da União (AGU), após um tempo na Justiça, o também pastor presbiteriano André Mendonça. 
origens temporais e geográficas junto às igrejas tradicionais, além de pensar em como estas têm atuado fortemente no momento presente (Fonseca, 2019).

\section{PARTIDOS, ELEIÇÕES E IDENTIDADE EVANGÉLICA}

A urgência dos desafios enfrentados na atualidade dá a exata percepção da importância de uma geração que tem inovado em estratégias e se posicionado de forma firme em diferentes temas. Também é importante salientar que qualquer análise atual precisa considerar esses desafios e suas respostas em uma perspectiva mais ampla, e é exatamente isso que é buscado no artigo de Vital da Cunha, representando uma importante contribuição de seu texto.

Nesse sentido penso ser importante avançar um pouco mais nesse olhar, abrangê-lo para a imbricada relação entre partidos políticos e seus arranjos e disputas internas que incluem a participação em processos eleitorais, os processos decorrentes que se estabelecem a partir da eleição e das realizações, e as agendas decorrentes de um mandato parlamentar.

Um primeiro aspecto importante que nos auxilia a matizar os desafios que se colocam na busca de fortalecimento da participação de grupos sociais na política pode ser dimensionado ao se considerar a participação de evangélicos em partidos políticos. No texto, o foco recaiu sobre candidaturas à esquerda selecionadas a partir de dois movimentos, a Bancada Evangélica Popular (BEP) e o Cristãos Contra o Fascismo (CCF). Esses movimentos participaram apoiando candidaturas em vários partidos de esquerda e ao consultar os dados do $\mathrm{TSE}^{9}$ para os candidatos apoiados pela BEP e conforme informaçóes do Instagram do $\mathrm{CCF}^{10}$ é possível concluir que apoiaram 47 candidatos a vereadores, em cerca de 20 municípios de 6 estados que somaram algo em torno de 90 mil votos.

${ }^{9}$ TRIBUNAL SUPERIOR ELEITORAL. Eleição Municipal Ordinária 2020. Disponível em: https://resultados.tse.jus.br/oficial/. Acesso em: 25 jun. 2021.

${ }^{10}$ Ver em: https://www.instagram.com/cristaoscontraofascismo/ 
Desses 47 candidatos dois foram eleitos e 15 ficaram como suplentes, o que, na grande maioria dos casos, simplesmente indica que obtiveram votação superior a $10 \%$ do quociente eleitoral exigido para que um vereador assuma uma das vagas na câmara municipal. Assim, tem-se que 30 desses candidatos não alcançaram o valor mínimo estipulado e ficaram designados como "não eleitos". Os suplentes podem estar em posição distante e são alguns poucos que potencialmente poderão vir a assumir o mandato.

Uma ponderação importante é considerar os dados de como essa presença evangélica em pleitos eleitorais se deu a partir de uma visão que considere a atuação de partidos constituídos. Olhar o mesmo ponto a partir de uma outra perspectiva. Certamente é a Igreja Universal do Reino de Deus (IURD), com sua história e experiência nesse campo, uma importante referência a ser considerada (Fonseca, 2003). São vários os trabalhos e estudos que exploram as dinâmicas, experiências e estratégias eleitorais adotadas pela IURD desde a década de 1980 com a eleição de Roberto Augusto para deputado federal constituinte, até os dias atuais com uma ampla bancada federal, tendo tido em figuras como o Bispo Rodrigues - que foi condenado a prisão por seis anos em 2013 por crimes de corrupçáo passiva e lavagem de dinheiro no caso que ficou conhecido como mensalão - uma importante liderança política nacional na década de 1990 e início do século 21 (Fonseca, 2008).

Foi em 2005 que a liderança da IURD assumiu um outro caminho para estabelecer sua presença na política com a criação do Partido Republicano do Brasil (PRB), hoje apenas conhecido como Republicanos. Um dos partidos com maior crescimento nas eleiçóes de 2020, é reconhecido como sendo um espaço da IURD, com seu presidente sempre ligado à denominação, mas não possuindo necessariamente entre os seus candidatos e quadros somente pessoas ligadas à igreja. Um levantamento da presença e eleição de evangélicos apoiados pelo Republicanos implicaria numa significativa pesquisa e, para efeitos desse diálogo, penso ser suficiente considerar as informaçóes que Tanaka (2020) nos oferece. A autora identificou que os candidatos lançados nas eleiçôes para vereador pelo Republicanos com a numeração 10.123 geralmente são figuras da IURD. O que para algumas cidades verificadas 
realmente foi um fato. Considerando essa hipótese como verdadeira temos que o Republicanos apresentou 1504 candidatos com esta numeração, no mesmo número de municípios, e cerca de 400 destes foram eleitos.

Considerando que o foco do artigo está nos evangélicos em partidos de esquerda, penso que considerar essa questáo no escopo do Partido dos Trabalhadores (PT) também pode ser um importante exercício. Novamente, somente considerando informações facilmente acessíveis por meio de reportagem recente, como a matéria de Roxo (2021) que informa que o PT contou com cerca de 2 mil candidatos que se declararam evangélicos e que concorreram ao cargo de vereador pelo partido em mil municípios de todos estados. Destes, 136 foram eleitos em 100 cidades e um pouco mais de mil ficaram como suplentes.

Assim, me parece ser fundamental nessa discussão sobre a presença de evangélicos em partidos, sejam de esquerda ou de direita, as estratégias e diretrizes político-partidárias existentes e de como estas se encontram ou não envolvidas em todo o processo de ligaçáo com as políticas identitárias que incluem a filiação religiosa como um aspecto. No caso da IURD há um processo centralizado vinculado à instituição que náo se faz presente somente no mundo da política formal, mas também é possível identificar que atua enquanto uma empresa de mídia e está presente em diversas outras áreas econômicas que incluem a construção civil, o sistema financeiro, entre tantas outras.

Já no caso do PT, o caminho é diferente e inclui o investimento no mapeamento e na realização de açôes que visam a organização desse segmento no interior do partido, envolvendo os seus militantes filiados que já atuam no partido. Assim se deu a criação do Núcleo de Evangélicas e Evangélicos do PT (NEPT) que em seu primeiro encontro nacional - realizado em São Paulo em abril 2019 e que reuniu cerca de 100 pessoas de todas as regióes do Brasil - afirmou em carta assinada pelos participantes:

Conclamamos a todas as evangélicas e evangélicos a se integrarem e organizarem Comitês Lula Livre por todos os cantos de sua atuação, reunindo 
irmãs e irmãos e atuando em coletivos, associações, sindicatos, universidades, diretórios municipais, estaduais e distrital do nosso partido.

E, por fim, compreendemos que é tarefa das evangélicas e evangélicos petistas organizar núcleos nos municípios, estados, territórios e no Distrito Federal, realizar ciclos de debates, estudos bíblicos e reuniôes de oração sobre a realidade, a defesa da democracia, pela liberdade de Lula e contra a reforma da Previdência ${ }^{11}$.

A questão religiosa enquanto identidade parece ser acionada nessa situação para reunir e aglutinar pessoas já envolvidas. Esse processo é distinto daquele capitaneado pela IURD em que a questão religiosa é parte de uma estratégia de campanha a partir da atuação da própria igreja, postura que também foi utilizada em processos de ocupação de espaços políticos e institucionais por ocasião da gestão do Bispo Crivella como Ministro da Pesca durante o governo da Presidenta Dilma Rousseff.

$\mathrm{O}$ que penso ser importante incluir nessa reflexão sobre a presença dos evangélicos em partidos de esquerda em sua "luta contra o Império" é que a atuação via questóes identitárias não é a única existente, e talvez seja a que possui uma abrangência menor em termos de público envolvido e votos alcançados. É certo que a evidência midiática e a presença nas redes sociais dessas iniciativas é maior, pois estas se constituem exatamente em meio à esta época e algumas captaram bastante bem as oportunidades e novas dinâmicas que são estabelecidas em nossa era digital.

Sabemos que os evangélicos não são somente as poderosas figuras midiáticas que povoam as redes sociais e os canais de televisão, geralmente masculinas e brancas. Também é sabido que as respostas existentes no campo social não se esgotam nas expressóes que defendem a igualdade de gênero, que assumem posturas antirracistas e que têm ocupado de forma destacada

${ }^{11}$ BRASIL DE FATO. Evangélicos do PT enviam carta ao povo e pedem democracia, igualdade e Lula livre. Disponível em: https://www.brasildefato.com.br/2019/04/08/evangelicos-do-pt-enviam-carta-ao-povo-e-pedem-democracia-igualdade-e-lula-livre. Acesso em: 29 jun. 2021.

Debates do NER, Porto Alegre, ANo 2 I, N. 39, P. I 37-I 53, JAN./JUl. 202 I 
uma série de espaços e fóruns públicos. Catapultados pelo acesso à Internet, há uma amplitude de movimentos e iniciativas que perpassam esses espaços e que envolvem algo que o artigo de Vital da Cunha comenta de passagem, a "questão geracional" e que, na fala de um dos entrevistados, aparece como uma diferença entre o que faz e pensa a "Velha Guarda" e aquilo que mobiliza e envolve jovens que até então não tinham "notoriedade". A diferença não é só geracional, há componentes de classe e outras complexidades que devem ser considerados. É fato que várias reportagens foram publicadas visando estas iniciativas identitárias e a notoriedade também tem chegado até essas lideranças que agora se veem, inclusive, dando entrevistas para uma pesquisa da Universidade.

Um ponto que para mim parece ser potente nesse processo de ingresso em partidos políticos passa exatamente por explorar as potencialidades que esta presença possui. Não uma entrada mediada por movimentos externos, que representam uma interessante inovação, mas também merece destaque o envolvimento que enfrenta os desafios da militância partidária. Nesse sentido, o Partido Socialismo e Liberdade (PSOL) parece ter um tipo de atuação mais organizada e direcionada para o público evangélico, envolvendo lideranças comunitárias e açóes direcionadas para o segmento. Cabe lembrar que foi por meio do partido que Cabo Daciolo, depois famoso por seus jargóes em que evocava "Deusxxx", foi eleito deputado federal.

Uma importante liderança evangélica do partido, com amplos espaços na mídia e nas redes sociais, é o Pastor Henrique Vieira que foi eleito vereador na cidade de Niterói em 2012 e que renunciou à possibilidade de retornar ao mandato no início de 2019, quando assumiria por ser primeiro suplente. Vieira optou por manter uma forte militância pública, destacando-se como uma liderança evangélica brasileira à esquerda, atuando tanto em questóes da sociedade civil, como também com destaque em seu partido, sendo assessor de um deputado estadual do PSOL.

No PSOL não há um núcleo evangélico, mas no caso do Rio de Janeiro é visível uma intencionalidade em relação à presença de representantes deste grupo nas eleiçôes. Um ponto importante a sublinhar é que isto também 
mostra o resultado de uma compreensão e do diálogo do partido com a realidade das cidades. Esse é um aspecto importante a considerar. A presença no território e o trabalho de base certamente resultarão na presença de evangélicos que participarão de processos e discussôes. Ao não negar ou agir contra essa realidade - a presença evangélica nas periferias das grandes cidades - se torna impossível a não existência de quadros evangélicos na composição de seus militantes. Considerar e estimular essa identidade, entre tantas outras, é que parece ser cada vez mais uma questão importante, especialmente diante das disputas que têm ocorrido no seio da comunidade religiosa.

Em relação ao PT, foi a partir dos movimentos de favelas do Rio de Janeiro que figuras, como a de Benedita da Silva, ganharam projeção na política nacional, tendo sido uma das primeiras mulheres negras a ter ocupado, na década de 1980 e no processo de redemocratização, o cargo de vereadora. É Deputada Federal por vários mandatos, foi Senadora, Ministra de Estado e Governadora. É comum e recorrente a afirmação feita por Benedita de que é petista e pentecostal.

No PSOL do Rio de Janeiro há outra liderança evangélica importante, Mônica Francisco, deputada estadual que era assessora da vereadora assassinada Marielle Franco. Ela foi uma das três candidatas eleitas que trabalhavam no gabinete da vereadora e que foram retratadas no documentário "Sementes - mulheres pretas no poder” (2020) de Éthel Oliveira e Júlia Mariano. Pensar no que representam as lideranças e mandatos de Mônica e Benedita pode ser útil para identificar as alternativas dessa presença evangélica em partidos de esquerda: a partir de mulheres negras que caminham também por meio de militâncias com uma longa história de engajamento e que envolvem diferentes esferas, sendo que, no caso das duas, estão relacionadas diretamente à realidade das favelas na cidade. É por meio de um lugar de legitimidade que se constituem as suas narrativas e identifico nas suas diferenças e semelhanças pontos importantes para se pensar indicativos de mudanças na política atual e de estratégias de transposição de determinadas pautas para o interior da política representativa. Compreendo como complementares boa parte das diferenças entre as narrativas adotadas na campanha das duas candidatas em 
2018, as quais acompanhei enquanto eleitor, sendo que é nessa intersecção que encontro um rico espaço a ser explorado visando pensar sobre uma atuação evangélica à esquerda na política partidária.

Primeiro é possível identificar nos discursos e postura das duas parlamentares uma percepção de um amplo processo histórico que considera os diversos avanços e lutas que foram se constituindo no contexto do processo de democratização antes e depois do final da ditadura civil-militar. A consciência desse processo mais amplo e de como se incluem outras questóes é um ponto que me parece importante no estabelecimento de forças e de estratégias que contribuam na atuação que se dá no campo da política formal.

Ainda sobre essa presença partidária é significativo salientar como isso resulta em maior ou menor apoio de uma estrutura que se coloca à disposição de possíveis candidatos, tanto em relação ao acesso à parcela do Fundo Especial de Financiamento de Campanha ou mesmo de recursos financeiros do apoio recebido de candidatos a outros cargos de um mesmo partido e que são destinados a apoiar outras candidaturas. $\mathrm{O}$ tempo ocupado na veiculação da campanha no horário eleitoral gratuito na televisão e no rádio e diferentes facilidades ou acessos são outras questôes que envolvem diversos aspectos e que não são de menor importância ao considerarmos uma disputa eleitoral.

Considerar esses processos e os desafios que representam para a atuação na política partidária é um desafio importante na construção de uma ainda limitada política representativa no Brasil. Recentes retrocessos, como a possibilidade de autofinanciamento, que pode ter como resultado a criaçáo de uma plutocracia, nos remetem a toda uma necessária discussão sobre investimento eleitoral (Mancuso, 2015), considerando inclusive a questão dos custos eleitorais e de como os gastos feitos nas campanhas importam para as eleiçôes (CEPESP/FGV, 2019).

É fundamental pensar essas questões junto a aspectos relacionados à inserção no território, como o trabalho com diversos grupos e o envolvimento nas estruturas partidárias, elementos importantes que vão se expressar de diversas formas, conforme o perfil e a atuação de lideranças evangélicas de 
esquerda envolvidas em movimentos sociais e na vida partidária. Considero ser relevante a questão estratégica que separa as diferentes narrativas a serem adotadas em campanhas proporcionais e as adotadas em majoritárias. A presença de candidaturas majoritárias que optam por assumir um discurso demarcado pelas questóes identitárias, não me parece ser uma marca de um "novo tempo" ou de mudanças que se estabelecem.

No texto a comparação escolhida foi entre as candidaturas à prefeita de Benedita da Silva em 2000 (PT/Rio de Janeiro) e a de Simoni dos Anjos em 2020 (PSOL/Osasco). Penso que poderia ser um outro "caso bom para pensar" analisar as mudanças em uma comparação entre a candidatura de Benedita em 2000 com a de 2020. O fato de Benedita da Silva ter sido candidata à prefeita nessas duas eleiçóes coloca em questão um interessante desafio que é observar as mutaçóes e as adaptaçóes que questóes relacionadas ao gênero e à raça ocuparam, ou não, no discurso da candidata nesses dois momentos. Como na atualidade essa questão foi abordada e como é possível identificar as mudanças em relação as composições sociodemográficas das votaçóes recebidas pela candidata nos dois momentos. Identifico que um exercício como esse poderia representar uma oportunidade para se aprofundar ainda mais parte das questóes provocadas pelo texto de Christina Vital da Cunha, que tive a feliz oportunidade de ler em primeira mão e aqui compartilhar minhas primeiras impressóes.

\section{REFERENCIAS}

AVELAR, Lúcia. Dos movimentos aos partidos: a sociedade organizada e a política formal. Politica \& Sociedade, n. 11, p. 101-16, 2007.

CARPENTER, Joel A. Revive Us Again: The reawakening of American Fundamentalism. New York: Oxford University Press, 1997.

CEPESP/FGV. CENTRO DE POLÍTICA E ECONOMIA DO SETOR PÚBLICO/FUNDAÇÃO GETÚLIO VARGAS. Os Custos da Campanha Eleitoral no Brasil: Uma análise baseada em evidência. São Paulo: FGV, 2019. 
Disponível em: https://www.cepesp.io/uploads/2019/05/Os-Custos-da-Campanha-Eleitoral-no-Brasil_Cepesp_BRAVA.pdf. Acesso em: 01 abr. 2021.

DEMIROVIC, Alex. El populismo autoritario como estrategia neoliberal de gestión de la crisis. Constelaciones. Revista de Teoría Crítica 10 (junio), p. 116-34, 2019.

FONSECA, Alexandre Brasil. Enfrentado o mal aqui fora: a Igreja Universal do Reino de Deus e sua prática política. Caminhos, Goiânia, v. 1, n.2, p. 11-32, 2003.

FONSECA, Alexandre Brasil. Religion and democracy in Brazil: a study of the leading evangelical politicians. In: FRESTON, Paul (Org.). Evangelical Christianity and Democracy in Latin America. Oxford: Oxford University Press, p. 163-206, 2008.

FONSECA, Alexandre Brasil. Discursos evangélicos de uma nova Direita Cristã à Brasileira. In: SOLANO, Esther (Org.). Brasil em colapso. São Paulo: Editora Unifesp, p. 105-120, 2019.

FONSECA, Alexandre Brasil. Indústria 4.0 e desigualdades: desafios para a educação. CADERNOS ADENAUER (SÃO PAULO), v. XXI, p. 143-163, 2020.

FONSECA, Alexandre Brasil. Revive Us Again: a deeper understanding of fundamentalism's continuing role in American life. In: ARRIGTON, A.; ADOGAME, A. (ed.). Festschrift for Joel Carpenter, no prelo, 2021.

KIRBY, Dianne. The Roots of the Religious Cold War: Pre-Cold War Factors. Soc. Sci., 7, 56, 2018.

KRUSE, Kevin. One Nation Under God: How Corporate America Invented Christian America. New York: Basic Books, 2015.

LACERDA, Mariana Basso. Neoconservadorismo de periferia: articulaçáo familista, punitiva e neoliberal na Câmara dos Deputados. Tese [Doutorado 
em Ciência Política] - Instituto de Estudos Sociais e Políticos, Universidade do Estado do Rio de Janeiro. Rio de Janeiro, 2018.

MANCUSO, Wagner Pralon. Investimento eleitoral no Brasil: balanço da literatura (2001-2012) e agenda de pesquisa. Rev. Sociol. Polit., Curitiba, v. 23, n. 54, p. 155-183, 2015.

NOVAES, Regina. A divina política: notas sobre as relaçôes delicadas entre religião e política. REVISTA USP, São Paulo, n. 49, mar/mai, p. 60-81, 2001. PHILIPS-FEIN, Kim. Invisible Hands: The Businessmen's Crusade Against the New Deal. New York: W.W. Norton, 2009.

ROXO, Sérgio. Atrair eleitores evangélicos ainda é desafio para a esquerda. Rio de Janeiro. O Globo 7 fev 2021. Disponível em: https://oglobo.globo.com/ brasil/atrair-eleitores-evangelicos-ainda-desafio-para-esquerda-24872839. Acesso em: 25 jun. 2021.

TANAKA, M. Resultados eleitorais, Republicanos e Igreja Universal. Blog Legis-Ativo. São Paulo, Estadão, 2020. Disponível em: https://politica. estadao.com.br/blogs/legis-ativo/resultados-eleitorais-republicanos-e-igreja-universal/. Acesso em 31 mar 2021.

ZUBOFF, Shoshana. Big Other: capitalismo de vigilância e perspectivas para uma civilização de informação. In: BRUNO, Fernando et al. (orgs). Tecnopolíticas da vigilância: perspectivas da margem. São Paulo: Boitempo, p. 17-68, 2018.

Recebido em: 05/04/2021

Aprovado em: 05/04/2021 



\section{RESPOSTA AOS COMENTÁRIOS}


